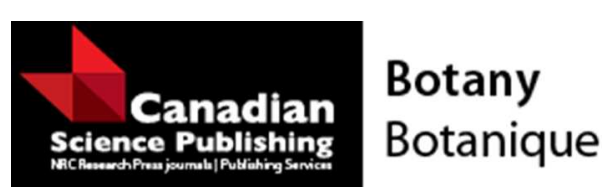

\title{
The Plant Vigor Hypothesis applies to a holoparasitic plant on a drought-stressed host
}

\begin{tabular}{|r|l|}
\hline Journal: & Botany \\
\hline Manuscript ID & cjb-2015-0099.R1 \\
\hline Manuscript Type: & Note \\
\hline Date Submitted by the Author: & $14-J u l-2015$ \\
\hline Complete List of Authors: & $\begin{array}{l}\text { Evans, Bethany; Illinois State University, School of Biological Sciences } \\
\text { Borowicz, Victoria; Illinois State University, School of Biological Sciences }\end{array}$ \\
\hline Keyword: & $\begin{array}{l}\text { Cuscuta gronovii, drought, host resistance, phloem feeders, Verbesina } \\
\text { alternifolia }\end{array}$ \\
\hline & \\
\hline
\end{tabular}

SCHOLARONE $^{\text {Im }}$

Manuscripts 
2 The Plant Vigor Hypothesis applies to a holoparasitic plant on a drought-stressed host

3

4 Bethany A. Evans and Victoria Borowicz

5 4120/School of Biological Sciences, Illinois State University, Normal, IL 61790-4120

$6 \quad$ USA

7 Bethany Evans: baevans@ilstu.edu

$8 \quad$ Victoria Borowicz: vaborow@ilstu.edu

9

10 Author for correspondence: Bethany Evans

11 Bethany Evans

12 School of Biological Sciences

13 Illinois State University

14 Campus Box 4120

15 Normal, IL 61790-4120 USA

16 Telephone: $309-438-5587$

17 FAX: 309-438-3722

18 baevans@ilstu.edu

19

20 


\section{Abstract}

22 Parasitic plants extract resources from host vascular tissues but their responses to

23 environmental fluctuation experienced by the host are poorly studied. Three frequently-

24 cited hypotheses for effects of environmental stress on plant resistance to herbivores

25 predict decreased, increased, or fluctuation in herbivore performance in response to

26 drought stress. We tested which hypothesis best accounts for how drought stress applied

27 to a perennial herb affects growth of the holoparasite, Cuscuta gronovii (common

28 dodder), an obligate shoot parasite. Verbesina alternifolia (wingstem) supporting single,

29 young C. gronovii were exposed to continuous, pulsed, or no water stress for $32 \mathrm{~d}$ and

30 then dry mass of each parasite was determined. Consistent with the Plant Vigor

31 Hypothesis, C. gronovii grew significantly better on well-watered hosts. Continuous and

32 pulsed drought stress of the host resulted in similar growth reduction relative to no

33 drought stress. In addition to reducing absolute growth of the holoparasite, continuous

34 and pulsed drought stress reduced the growth of the holoparasite relative to host growth.

35 Although functionally similar to insect phloem feeders, growth of holoparasites such as

36 C. gronovii is constrained by source-sink relations. Our results suggest drought stress

37 experienced by a host weakens source strength and reduces uptake by the holoparasite

38 acting as a sink.

39 Keywords: Cuscuta gronovii, drought, host resistance, phloem feeders, Verbesina

40 alternifolia, parasitic plant 


\section{Introduction}

43 Approximately $1 \%$ of flowering plant species in 18 families are considered to be

44 parasitic (Nickrent 2002; Westwood et al. 2010). This designation is based on formation

45 of a haustorium, an organ bridging host and parasite phloem or xylem (Kujit 1969).

46 Through these structures parasites extract a variety of resources from their hosts,

47 including photosynthates, solutes, and metabolites (Watling and Press 2001; Smith et al.

48 2013). Some parasitic plants, termed holoparasites, are functionally non-photosynthetic.

49 Because these species are fully dependent on hosts for resources transported in the host's

50 xylem and phloem streams, they may be subject to fluctuations in resource availability

51 following water stress experienced by the host.

52 Parasitic plants are important constituents of many terrestrial ecosystems and

53 economically important pests (Parker 2012). Nonetheless, the ecology of parasitic plant-

54 host responses to drought is poorly known. By contrast, drought-mediated interactions

55 between herbivores and host plants have been examined extensively (Huberty and Denno

56 2004, Joern and Mole 2005, Mody et al. 2009, Gutbrodt et al. 2011). Similarities in

57 feeding mode of holoparasitic plants and herbivorous insects (Pennings and Callaway

58 2002; Pennings and Simpson 2008) and hormone signaling in parasitized hosts (Runyon

59 et al. 2010) suggest that hypotheses for effects of plant drought stress on herbivore

60 performance may predict responses of holoparasitic plants.

61 Two long-standing hypotheses postulated to explain patterns of herbivore

62 performance predict opposite effects of environmental stress experienced by the host

63 plant. The Plant Stress Hypothesis assumes that stress increases availability of nutrients 
64 or decreases secondary metabolites, resulting in greater herbivore preference for or 65 performance on stressed plants (White 1969). The Plant Vigor Hypothesis predicts 66 greater herbivore abundance on rapidly-growing, vigorous plants or plant modules for a

67 variety of reasons, including greater concentrations or accessibility of quality nutrients

68 (Price 1991). A third hypothesis, the Pulsed-stress Hypothesis, predicts the best

69 performance by phloem, mesophyll, and xylem feeders (sap feeders) on plants

70 experiencing intermittent drought stress because drought induces increases in plant

71 nitrogen compounds that become available to sap feeders when turgor is regained

72 (Huberty and Denno 2004).

73 Here we test the three hypotheses (above) for effects of host plant stress on

74 holoparasite-host interactions. Because their haustoria bridge the parasite and host

75 vascular tissues, holoparasites may be postulated to feed in a manner similar to phloem

76 and xylem feeding herbivores (Marquardt and Pennings 2010; Pennings and Callaway

77 2002; Pennings and Simpson 2008). We relate holoparasites to phloem-feeding

78 herbivores because feeding guild is one of the best predictors of insect response to plant

79 stress (Huberty and Denno 2004; Koricheva et al. 1998) and holoparasites acquire

80 resources primarily from host phloem (Jeschke et al. 1994).

81 We conducted a greenhouse study of the effects of drought stress of the perennial

82 plant Verbesina alternifolia (L.) Britton ex Kearney (wingstem) on resistance and

83 tolerance to parasitism by the holoparasite Cuscuta gronovii Willd. Ex Schultes (common

84 dodder). The impact of drought stress on host response to parasitism (tolerance) has been

85 published elsewhere (Evans and Borowicz 2013). Here we focus on effects on 
86 holoparasite growth as a measure of quantitative resistance to determine which of the

87 three hypotheses best predicts behavior of this holoparasite-host system.

88 Through transport of the small seeds, Cuscuta spp. have spread to many parts of the

89 world and are economically important weeds for many crops, including cranberry,

90 clovers, alfalfa, and soybean (Parker 2012). Cuscuta gronovii is the most common and

91 abundant species of Cuscuta in North America (Sandler 2001). Stems of this annual

92 twine around a host and connect to its vascular tissue via searching hyphae that

93 differentiate into either xylem or phloem elements (Birschwilks et al. 2006). Both

94 Verbesina alternifolia (Asteraceae) and C. gronovii (Cuscutaceae) grow in thickets,

95 woods, and bottomlands throughout the Midwestern and Eastern United States (Gleason

96 and Cronquist 1991) in areas subject to prolonged or repeated episodes of drought.

\section{$98 \quad$ Materials and methods}

99 Methods were provided previously (Evans and Borowicz 2013) and details pertinent

100 to performance of C. gronovii are summarized here. Cuscuta gronovii and Verbesina

101 alternifolia are both native plants of central Illinois and were found to be in a host-

102 parasite relationship naturally. Seeds of both species collected in Lexington, McLean

103 County, Illinois, USA in October 2010 were cold stratified for $278 \mathrm{~d}$ ( $\mathrm{V}$. alternifolia) or

$104188 \mathrm{~d}($ C. gronovii) in plastic bags with damp Perlite $\mathrm{TM})$ in a $3^{\circ} \mathrm{C}$ refrigerator prior to

105 germination. On day 0 (22 d after cold stratification ended) $V$. alternifolia seedlings were

106 transplanted individually into $1.7 \mathrm{~L}$ pots containing $1: 1 \mathrm{MetroMix}^{\mathrm{TM}} 510:$ Perlite $^{\mathrm{TM}}$ on

107 greenhouse benches with $14 \mathrm{~h}$ of supplemental light. On days 11 and 22 each $V$. 
108 alternifolia was fertilized with $1 \mathrm{~g}(12-4-8 \mathrm{~N}-\mathrm{P}-\mathrm{K})$ of a slow-release granular fertilizer.

109 No pests were observed during the course of the experiment.

110 C. gronovii seeds were placed on top of a mixture of soil, sand, and Perlite ${ }^{\mathrm{TM}}$ to

111 germinate. On day 12, C. gronovii seedlings (3-6 cm long) were placed singly in small, 1

112 dram glass shell vials filled with water and haphazardly assigned to $90 \mathrm{~V}$. alternifolia.

113 Vials were placed within $2 \mathrm{~cm}$ of the main stem of the host. The seedling was considered

114 to be attached when it completed one tight $360^{\circ}$ loop around the host stem and this date

115 was recorded. Bamboo skewer sticks were placed in each pot. Velcro ${ }^{\mathrm{TM}}$ strips were used

116 if necessary to secure aggressively growing parasites to the bamboo stick in order to

117 prevent spread to other pots. Therefore, the parasite could only attach to the assigned

118 host. C. gronovii made multiple attachments on the host; however the number of

119 attachments was not recorded. Because $V$. alternifolia seeds were collected from the field

120 we anticipated some variation in growth rates due to genotypic differences and conditions

121 experienced by the mother. On day 13 we recorded the length of the longest leaf on each

122 host as a measure of pre-treatment host size.

123 Thirty $V$. alternifolia were randomly assigned to each of three treatments (control,

124 persistently drought stressed, or pulsed drought stressed). On day 25, each pot was

125 watered to excess with $500 \mathrm{ml}$ of water and weighed 30 minutes later to determine initial

126 saturation mass (ISM), a benchmark for all treatments. Control plants were maintained at

$127>85 \%$ of ISM. Continuously stressed treatment pots were watered to $45 \%$ of ISM after

128 the pot was $<40 \%$ of ISM. Pulse-stressed pots received no water until any of 10 sentinel

129 pots declined to $35 \%$ ISM, then watered to 100\% ISM. Pulse-stressed pots were brought 
130 to ISM twice and the experiment was terminated on $\mathrm{d} 57$ when these pots needed a third

131 pulse of water. Pulsed and continuous drought treatments received similar amounts of

132 water over the course of the experiment. Cuscuta gronovii were removed from host

133 shoots and dried at $60^{\circ} \mathrm{C}$ to constant weight. Shoots and roots of $V$. alternifolia were also

134 harvested, dried, and weighed.

135 Eleven $C$. gronovii failed to attach to the host at least $4 \mathrm{~d}$ before drought stress began

136 and were excluded prior to analysis, ensuring that all parasites were well-established at

137 the onset of drought stress. Twenty-six controls, 28 pulse-stressed, and 25 continuously-

138 stressed pots were included in the analyses $(n=79)$. Data were transformed to meet the

139 assumptions of normality and homoscedasticity. All statistical analyses were performed

140 using SAS 9.2 (C) 2008.

141 Dry mass of C. gronovii was analyzed by analysis of covariance with length of the

142 longest host leaf as covariate to determine the effects of host water stress on resistance to

143 parasitism. To determine if the parasite was limited by the amount of the host plant

144 available, parasite mass $\mathrm{g}^{-1}$ of total host mass (shoot and root mass combined) was

145 analyzed with ANCOVA using duration of attachment to the host as the covariate. When

146 shade treatment was significant, differences among means were analyzed using

147 orthogonal comparisons (Sokal and Rohlf 2012).

\section{$148 \quad$ Results}

149 Over $45 \%$ of the C. gronovii attached within one day and $90 \%$ within three days of 150 placement. Drought stress applied to hosts significantly affected the dry mass of $C$.

151 gronovii $\left(F_{2,75}=61.73, P<0.0001\right)$. Mean mass of $C$. gronovii on well-watered hosts was 
$152>2 \mathrm{x}$ that of those on drought-stressed hosts $\left(F_{1,75}=123.28, P<0.0001\right.$; Fig. 1A).

153 However, holoparasite growth did not differ between pulsed- and continuously-stressed

154 hosts $\left(F_{1,75}=0.68, P=0.4116\right)$. Cuscuta gronovii mass increased significantly with the

155 length of the longest host leaf prior to the start of treatments $\left(F_{1,75}=4.06, P=0.0474\right)$.

156 Analysis of parasite mass $\mathrm{g}^{-1}$ of host indicated that parasite growth was not strictly

157 linked to the amount of host available. Water treatment significantly affected the

158 parasite:host ratio $\left(F_{2,75}=3.9, P=0.01\right)$ and $C$. gronovii on well-watered hosts produced

159 more than $25 \%$ more dry mass per gram of dry host mass compared to growth on

160 drought-stressed hosts $\left(F_{1,75}=7.78, P=0.0067\right)$. Growth of $C$. gronovii per gram of host

161 did not differ between continuously-stressed and pulse-stressed hosts $\left(F_{1,75}=0.04, P=\right.$

162 0.8458; Fig. 1B). Although most C. gronovii attached to hosts within 3 days, the duration

163 of attachment ranged from 37 days to 44 days and longer duration of attachment resulted

164 in greater final mass $\left(F_{1,75}=6.98 P=0.0100\right)$.

\section{Discussion}

167 Well-watered V. alternifolia grew most rapidly (Evans and Borowicz 2013) and

168 supported the largest C. gronovii, consistent with the Plant Vigor Hypothesis. Interim

169 measurements were not taken and it is possible that pulse-stressed hosts supported more

170 rapid C. gronovii growth during intervals of relief from drought. Nonetheless,

171 holoparasite growth over the course of three bouts of intermittent drought stress was

172 similar to growth on continuously-stressed plants, refuting the Pulse-stress Hypothesis. 
173 Often portrayed as mutually exclusive, the Plant Vigor and the Plant Stress

174 hypotheses may each usefully describe patterns of herbivore performance if type of tissue

175 consumed is considered (White 2009). Increased performance of phytophages accessing

176 nutrients translocated from mature tissue ("senescence feeders") is likely to be predicted

177 by the Plant Stress Hypothesis and increased performance of phytophages obtaining

178 nutrients translocated into new growth ("flush feeders") is likely to be predicted by the

179 Plant Vigor Hypothesis (White 2009). Unlike individual insects, one Cuscuta plant

180 maintains multiple haustoria of varying ages on one or more hosts. Due to prolonged

181 attachment and extensive growth, Cuscuta and other holoparasites may feed

182 simultaneously as flush-feeders from recent attachments and early in the season when

183 hosts are growing, and as senescence-feeders from older haustoria and later in the season

184 as hosts reallocate metabolites. This hypothesis would be readily tested with Cuscuta and

185 suggests avenues for future research. Regardless, in the present experiment, C. gronovii

186 clearly performed better on more vigorous, unstressed hosts.

187 Although holoparasites and aphids feed in analogous ways from the same plant part,

188 the analogy may break down for mechanism of resource acquisition. Using fine stylets,

189 aphids pierce phloem and feed passively due to high turgor pressure within the sieve

190 elements (Guerrieri and Digilio 2008). Transfer of proteins (Haupt et al. 2001),

191 fluorescent dyes (Birschwilks et al. 2006), viruses (Hosford, 1967), and mRNA (Roney et

192 al. 2007) from host to other species of Cuscuta strongly suggests symplasmic continuity.

193 Both C. gronovii and aphids may have direct contact with host cell contents; however

194 movement to Cuscuta occurs because the holoparasite creates a very efficient nutrient

195 sink (Wolswinkel 1984; Vaughn 2006; Smith et al. 2013). Unlike aphids, which are 
196 much smaller than their hosts, C. gronovii mass can exceed that of its host (Fig. 1b). By

197 creating a strong sink, the holoparasite deprives host roots of carbon, leading to increased

198 host photosynthesis and flow of resources to the holoparasite (Jeschke et al. 1994;

199 Jeschke and Hilpert1997). Drought-stressed plants close stomata to reduce transpiration

200 and photosynthesis declines (Xu et al. 2010). This reduces uploading and translocation

201 of resources in the phloem stream, decreasing access by the holoparasite. Resistance to

202 parasitism, as measured by holoparasite growth, is consequently greater when hosts are

203 drought stressed.

204 Many climate change models predict increased variability in precipitation and 205 regional droughts (Dore 2005; IPCC 2007). While the impact of drought on plant-

206 herbivore systems has received considerable attention (e.g., Mody et al. 2009; Johnson et

207 al. 2011; Grinnan et al. 2013), less is known about drought effects on parasitic plants as

208 consumers. Similar to insects, holoparasites can be potent pests (Dawson et al. 1994;

209 Sandler 2001; Parker 2010) and have also been considered as agents of biocontrol (Shen

210 et al., 2005; Yu et al. 2009, 2011). Studies that examine the impact of the abiotic

211 environment on holoparasite-host interactions provide context for better understanding

212 the role of holoparasites in natural communities and also as pests and biocontrol agents.

213 Our study indicates that whether continuous or episodic, drought will reduce performance

214 of holoparasites on stricken hosts and the impact is greater than would be accounted for 215 through reduced host growth. 


\section{Acknowledgments}

218 We thank J. Evans Campbell and D.J. Schmidt for assistance, J.E. Armstrong for useful

219 discussion, and S.A. Juliano for insightful comments and statistical guidance. Special

220 thanks to the ParkLands Foundation for granting permission to collect seeds necessary for

221 this research.

229 Data accessibility

230 Data will be deposited at ISU ReD: Research and eData at

231 http://ir.library.illinoisstate.edu 


\section{References}

234 Birschwilks, M., Haupt, S., Hofius, D., and Neumann, S. 2006. Transfer of phloem-

235 mobile substances from the host plants to the holoparasite Cuscuta sp. J. Exp. Bot. 57:

236 911-921. doi:10.1093/jxb/erj076.

237 Dawson, J.H., Musselman, L.J., Wolswinkel, P., and Dörr, I. 1994. Biology and control

238 of Cuscuta. Rev. Weed Sci. 6: 265-317.

239 Dore, M.H.I. 2005. Climate change and changes in global precipitation patterns: what do

240 we know? Environ. International 31: 1167-1181. doi:10.1016/j.envint.2005.03.004.

241 Evans, B., and Borowicz, V. 2013. Verbesina alternifolia tolerance to the holoparasite

242 Cuscuta gronovii and the impact of drought. Plants 2: 635-649.

243 doi:10.3390/plants2040635.

244 Gleason, H.A., and Cronquist, A. 1991. Manual of vascular plants of Northeastern United

245 States and adjacent Canada. 2d ed. New York Botanical Garden, New York.

246 Grinnan, R., Carter, T.E. Jr, and Johnson, M.T.J. 2013. The effects of drought and

247 herbivory on plant-herbivore interactions across 16 soybean genotypes in a field

248 experiment. Ecol. Entomol. 38: 290-302. doi:10.1111/een.12017.

249 Guerrieri, E., and Digilio, M.C. 2008. Aphid-plant interactions: a review. J. Plant

250 Interact. 3:223-232. doi:10.1080/17429140802567173.

251 Gutbrodt, B., Mody, K. and Dorn, S. 2011. Drought changes plant chemistry and causes

252 contrasting responses in lepidopteran herbivores. Oikos 000: 001-009.

253 doi:10.1111/j.1600-0706.2011.19558.x. 
254 Haupt, S., Oparka, K.J., Sauer, N., and Neumann, S. 2001. Macromolecular trafficking 255 between Nicotiana tabacum and the holoparasite Cuscuta reflexa. J. Exp. Bot. 52: 256 173-177. doi:10.1093/jexbot/52.354.173.

257 Hosford, R.M.J. 1967. Transmission of plant viruses by dodder. Bot Rev 42: 387-406. 258 doi:10.1104/pp.106.088369.

259 Huberty A F, and Denno R F. 2004. Plant water stress and its consequences for 260 herbivorous insects: a new synthesis. Ecology 85: 1383-1398. doi:10.1890/03-0352. 261 IPCC, 2007: Climate Change 2007: The Physical Science Basis. Contribution of Working 262 Group I to the Fourth Assessment Report of the Intergovernmental Panel on Climate 263 Change [Solomon, S., D. Qin, M. Manning, Z. Chen, M. Marquis, K.B. Averyt, 264 M.Tignor and H.L. Miller (eds.)]. Cambridge University Press, Cambridge, United 265 Kingdom and New York, NY, USA.

266 Jeschke, W.D., and Hilpert, A. 1997. Sink-stimulated photosynthesis and sink-dependent 267 increase in nitrate uptake: nitrogen and carbon relations of the parasitic association 268 Cuscuta reflexa-Ricinus communis. Plant Cell Environ. 20: 47-56. doi:10.1046/j.1365269 3040.1997.d01-2.x.

270 Jeschke, W.D., Rath, N., Baumel, P., Czygan, F.C., and Proksch, P. 1994. Modeling the 271 flow and partitioning of carbon and nitrogen in the holoparasite Cuscuta reflexa Roxb 272 and its host Lupinus albus L. 1. Methods for estimating net flows. J. Exp. Bot. 45: 273 791-800. doi:10.1093/jxb/45.6.801.

274 Joern, A. and Mole, S. 2005. The plant stress hypothesis and variable responses by blue 275 grama grass (Bouteloua gracilis) to water, mineral nitrogen, and insect herbivory. J.

276 Chem. Ecol. 31: 2069-2090. doi:10.1007/s10886-005-6078-3. 
277 Johnson, S.N., Staley, J.T., McLeod, F.A.L., and Hartley, S.E. 2011. Plant-mediated

278 effect of soil invertebrates and summer drought on above-ground multitrophic

279 interactions. J. Ecol. 99: 57-65. doi:10.1111/j.1365-2745.2010.01748.x.

280 Koricheva, J., Larsson, S., and Haukioja, E. 1998. Insect performance on experimentally

281 stressed woody plants: a meta-analysis. Annu. Rev. Entomol. 43: 195-216.

282 doi:10.1146/annurev.ento.43.1.195.

283 Kuijt, J. 1969. The biology of parasitic flowering plants. University of California Press,

284 Berkeley, California.

285 Marquardt, E.S., and Pennings, S.C. 2010. Constraints on host use by a parasitic plant.

286 Oecologia 164: 177-184. doi:10.1007/s00442-010-1664-7.

287 Mody, K., Eichenberger, D., and Dorn, S. 2009. Stress magnitude matters: different

288 intensities of pulsed wager stress produce non-monotonic resistance responses of host

289 plants to insect herbivores. Ecol. Entomol. 34: 133-134. doi:10.1111/j.1365-

$290 \quad 2311.2008 .01053 . x$.

291 Nickrent, D.L. 2002. Parasitic Plants of the World. In Parasitic Plants of the Iberian

292 Peninsula and Balearic Islands. Edited by J.A. López-Sáez, P. Catalán, and L. Sáez.

293 Mundi-Presna Libros, S.A., Madrid. pp. 7-27.

294 Parker, C. 2012. Parasitic Weeds: A World Challenge. Weed Sci. 60: 269-276.

295 doi:10.1614/WS-D-11-00068.1.

296 Pennings, S.C., and Callaway, R.M. 2002. Parasitic plants: parallels and contrasts with

297 herbivores. Oecologia 131: 479-489. doi:10.1007/s00442-002-0923-7.

298 Pennings, S.C., and Simpson, J.C. 2008. Like herbivores, parasitic plants are limited by

299 host nitrogen content. Plant Ecol. 196: 245-250. doi:10.1007/s11258-007-9348-z. 
300 Price, PW. 1991. The plant vigor hypothesis and herbivore attack. Oikos 62: 244-251. 301 Roney, J.K., Khatibi, P.A., and Westwood, J.H. 2007. Cross-species translocation of 302 mRNA from host plants into the parasitic plant dodder. Plant Physiol. 143: 1037$303 \quad$ 1043. doi:10.1104/pp.106.088369.

304 Runyon, J.B., Mescher, M.C., Felton, G.W., and De Moraes, C.M. 2010. Parasitism by 305 Cuscuta pentagona sequentially induces JA and SA defence pathways in tomato. 306 Plant Cell Environ. 33: 290-303. doi:10.1111/j.1365-3040.2009.02082.x.

307 Sandler, H.A. 2001. Dodder - Cuscuta gronovii Willd. Cranberry Experiment Station, 308 University of Massachusetts, Wareham, MA.

309 Shen, H., Ye, W., Hong, L., Cao, H, and Wang, Z. 2005. Influence of the obligate 310 parasite Cuscuta campestris on growth and biomass allocation of its host Mikania 311 micrantha. J. Exp. Bot. 56: 1277-1284. doi:10.1093/jxb/eri128.

312 Smith, J.D., Mescher, M.C., and De Moraes, C.M. 2013. Implications of bioactive solute 313 transfer from hosts to parasitic plants. Curr. Opin. Plant Biol. 16: 464-472.

314 doi:10.1016/j.pbi.2013.06.016.

315 Sokal, R.R., and Rohlf, F.J. 2012. Biometry: The principles and practice of statistics in 316 biological research. $4^{\text {th }}$ ed., W.H. Freeman and Co., New York.

317 Vaughn, K.C. 2006. Conversion of the searching hyphae of dodder into xylic and phloic 318 hyphae: a cytochemical and immunocytochemical investigation. Int. J. Plant Sci. 167: 319 1099-1114. doi:10.1086/507872.

320 Watling, J.R. and Press, M.C. 2001. Impacts of infection by parasitic angiosperms on 321 host photosynthesis. Plant Biol. 3: 244-250. doi:10.1055/s-2001-15195. 
322 Westwood, J.H., Yoder, J.I., Timko, M.P., dePamphilis, C.W. 2010. The evolution of

323 parasitism in plants. Trends in Plant Science 15: 227-235.

324 doi:10.1016/j.tplants.2010.01.004.

325 White, T.C.R. 1969. An index to measure weather-induced stress of trees associated with

326 outbreaks of psyllids in Australia. Ecology 50: 905-909. doi:10.2307/1933707.

327 White, T.C.R. 2009. Plant vigour versus plant stress: a false dichotomy. Oikos 118: 807-

328 808. doi:10.1111/j.1600-0706.2009.17495.x.

329 Wolswinkel, P. 1984. Phloem unloading and 'sink strength': the parallel between the

330 site of attachment of Cuscuta and developing legume seeds. Plant Growth Regulation

331 2: 309-317. doi:10.1007/BF00027290.

$332 \mathrm{Xu}, \mathrm{Z}$., Zhou, G., and Shimizu, H. 2010. Plant responses to drought and rewatering. Plant

333 Signal. Behav. 5: 649-654. doi:10.4161/psb.5.6.11398.

334 Yu, H., Liu, J., He, W.M., Miao, S.L., and Dong, M. 2009. Restraints on Mikania

335 micrantha by Cuscuta campetris facilitates restoration of the disturbed ecosystem.

336 Biodiversity 10: 72-78. doi:10.1080/14888386.2009.9712847.

337 Yu, H., Liu, J., He, W.M., Miao, S.L., and Dong, M. 2011. Cuscuta australis restrains

338 three exotic invasive plants and benefits native species. Biol. Invasions 13: 747-756.

339 doi:10.1093/aobpla/plv031. 
$340 \quad$ Figure captions.

341 Fig. 1. Least squares mean $( \pm$ s.e. $)$ of $C$. gronovii $(a)$ dry mass, and $(b)$ dry mass $\mathrm{g}^{-1}$ dry host 342 mass when the host $V$. alternifolia was well watered, pulse-stressed, or continuously drought 343 stressed. $* * *=P<0.0001 . * *=P<0.01$. 

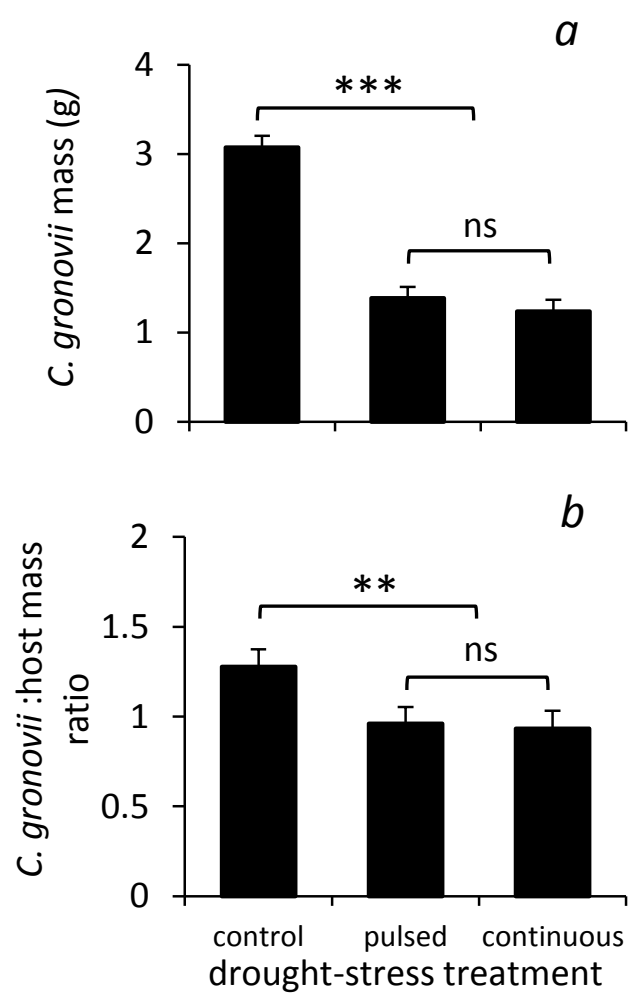